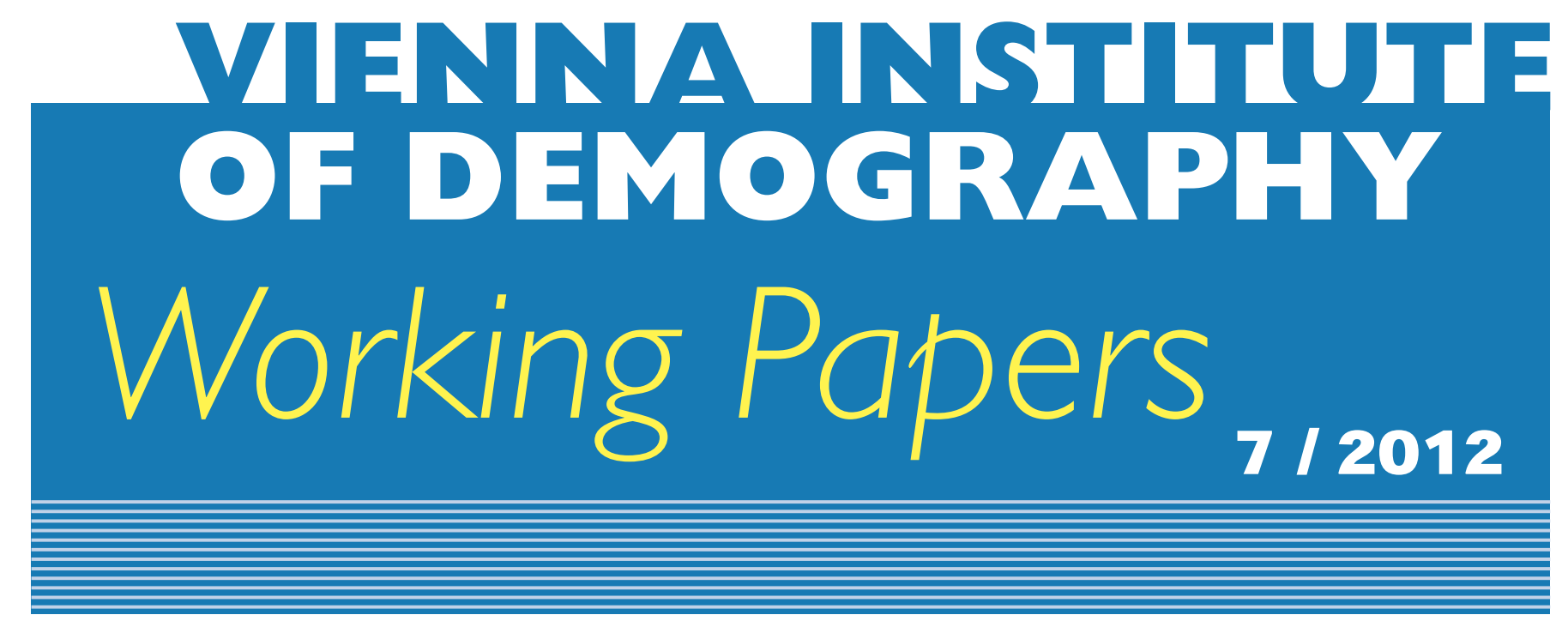

Maria Rita Testa, Laura Cavalli, and Alessandro Rosina

\title{
The Decision of Whether to Have a Child: Does Couple Disagreement Matter?
}

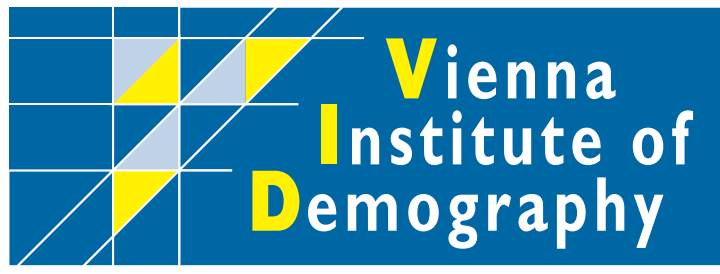

Vienna Institute of Demography Austrian Academy of Sciences

Wohllebengasse I2-14

A-I040Vienna $\cdot$ Austria

E-Mail:vid@oeaw.ac.at

Website: www.oeaw.ac.at/vid 


\begin{abstract}
Most of the international studies on fertility are based on a female perspective. A major difficulty in couple-level research is the need for high-quality data that includes information on both partners. Using couple data from a longitudinal study conducted in Italy [2003-2007], a country with persistently low fertility levels, we examined the effect of disagreement within a couple about childbearing behaviour. The starting point was the hypothesis advanced in an earlier study that Italian women prevail in reproductive decision-making, because childbearing lies mainly in their sphere of influence. The data revealed that the decision rules are parityspecific. At parities zero and one, the disagreement produced an intermediate childbearing outcome irrespective of which partner wanted a(nother) child; while at higher parities, an asymmetrical veto power model in which the female partner had greater influence was observed. The findings suggest that the predictive power of short-term fertility intentions strongly improves if both partners' views are considered in fertility models, and thus support the adoption of couple analysis in fertility research.
\end{abstract}

\title{
Keywords
}

Fertility decision-making, reproductive behaviour, couple disagreement, childbearing intentions, child-timing intentions, partner context.

\section{Authors}

Maria Rita Testa, Wittgenstein Centre for Demography and Global Human Capital (IIASA, VID/ÖAW, WU), Vienna Institute of Demography/Austrian Academy of Sciences.

Email: maria.rita.testa@oeaw.ac.at

Laura Cavalli, University of Verona. Email: laura.cavalli@univr.it

Alessandro Rosina, Catholic University of Milan. Email: alessandro.rosina@unicatt.it

\section{Acknowledgments}

This paper was presented at the Annual Meeting of the Population Association of America held in San Francisco on May 3-5, 2012, and at the European Population Conference held in Stockholm on June 13-16, 2012. We thank all of the colleagues present at these conferences for their valuable comments on our paper. Any shortcomings are the responsibility of the authors. 


\title{
The Decision of Whether to Have a Child: Does Couple Disagreement Matter?
}

\author{
Maria Rita Testa, Laura Cavalli, and Alessandro Rosina
}

\section{Introduction}

There is a widespread agreement in the international literature about the importance of men in reproductive decision-making (Ryder 1973), and a number of authors have adopted a couple-oriented approach in their fertility research (Fried and Udry 1979; Coombs and Chang 1981; Beckman et al. 1983; Morgan 1985; Thomson et al. 1990; Corijn et al. 1996; Thomson 1997; Thomson and Hoem 1998; Jansen and Liefbroer 2006; Miller and Pasta 1996; Miller et al. 2004; Becker 1996; Fraboni, Rosina 2006, Rijeken and Thomson 2010; Rijken and Liefbroer 2009; Testa 2010 and 2012a). However, most of the studies on fertility continue to be primarily based on the female perspective. This choice is usually justified by the high degree of homogamy within the couple, and the fact that women are the main actors and the most reliable reporters of childbearing events.

A major difficulty in couple-level research lies in the need to have high-quality survey data that include information on both partners, possibly in repeated waves. These data are indispensable for researchers who want to ascertain the differences between partners' reproductive goals, and to identify the contribution of each member of the couple to the final childbearing outcome. While this is true in general, a lack of adequate data is an even greater problem in European countries, where longitudinal household surveys have only rarely been conducted in recent decades.

In this paper, we address the issue of fertility decision-making using longitudinal data on couples that spans a three-year period (from the end of 2003 to the beginning of 2007). This study is based on a couple longitudinal dataset derived from the "Family and Social Survey," conducted by the Italian National Institute of Statistics (ISTAT) in 2003-2007, which provides us with a unique opportunity to investigate the fertility behaviour of couples. We address the following research questions: What rules are applied in resolving conflicts within couples about short-term fertility intentions, and what is the ultimate childbearing outcome of these conflicts? Does one of the partners prevail in the final decision? Does intra-family bargaining power influence the couple's final decision?

Italy is a country in which the two-child norm is still predominant among women and men of reproductive ages, but actual fertility has long been well below this norm (Rosina 2004; Testa 2006 and 2012b). The desired number of children among Italians is, on average, two children per woman, but the cohort completed fertility rates for Italian women born in 1960 is 1.4. Moreover, because gender inequality and a dearth of support for combining childrearing and employment, working women may face larger gaps between their desired and their actual family size than women who do not participate in the labour market (Cavalli 2010; 
Testa 2012b). The lack of agreement with the partner may be an important reason for not satisfying a desire to have a child. Therefore, an analysis of the effect of couple conflict on childbearing behaviour is an important contribution in this research area, both in terms of scientific knowledge and policy implications.

The remainder of the paper is organized as follows. First, we review the existing literature on fertility intentions and behaviour among couples. We then present our hypotheses, data, and methodology. This is followed by a description of the main statistical findings. In the final section, we discuss alternative interpretations of the results, as well as possible caveats inherent to the analysis. An Appendix describing the robustness of the results to alternative definitions of couple disagreement is a complement to the main analysis.

\section{Theories on Fertility Decision-Making}

There are two major theoretical frameworks suitable for studying fertility decisionmaking: the theory of planned behaviour (TPB) and the theory of traits-desires-intentionsbehaviour (TDIB). In the following, we examine how they take into account the dyadic aspect of reproduction.

The theory of planned behaviour (Ajzen 1991) has been applied in the domain of fertility decision-making (Billari et al. 2009; Dommermuth et al. 2011). It studies intentions as an immediate forerunner of the corresponding behaviour, and views intentions as being formulated under the immediate influence of three groups of factors: (a) personal positive and negative attitudes towards the behaviour, i.e., having a child; (b) subjective norms, i.e., perceived social pressure to engage or not to engage in the behaviour; and (c) perceived behavioural control, i.e., the ability to perform the behaviour, which may depend, for example, on the availability of housing, income, or other resources. The partner's intentions are not explicitly considered in the theory, but it may be implicitly assumed that the perception of a disagreement with the partner may influence an individual's normative beliefs. An individual who wants to have a(nother) child, and who perceives that his/her partner does not share this wish, is likely to form the belief that the partner does not want her/him to have a(nother) child. This perception may influence the respondent's own fertility intentions. In a recent conference on reproductive decision-making, Ajzen clarified that the close link between intentions and subsequent behaviour holds true only if the behaviour is specified in all of its four components: namely, the target, the action, the context, and the time (Ajzen 2010). In the field of fertility, the target is a child, the action is giving birth, the context is the couple, and the time could be a short-term horizon, which may make the intentions more realistic. Consistent empirical evidence has been collected on the crucial importance of the partner's context for the construction of pregnancy intentions (Barret and Wellings 2002; Zabin et al. 2000). Although it can be adapted to incorporate the partner's dimension, the theory of planned behaviour does not explicitly consider the complexity of the dyadic nature of reproduction (Philipov 2011), nor does it describe the disagreement effects of a couple's decisional conflicts (Miller 2011a; Miller and Pasta 1996). 
The traits-desires-intentions-behaviour theory (Miller 1986 and 1994) sees the behaviour that determines whether or not a pregnancy occurs as the last step of a motivational sequence that encompasses four major stages. The first one refers to motivational traits, or the dispositions to feel, think, and behave in certain ways with respect to fertility; the second stage concerns desires, emotional feelings, or conscious wishes that do not lead directly to action; the third stage refers to intentions, desires constrained by reality, and psychological states that represent conscious commitment to act in a certain way or to achieve a certain goal at some future time. The eventual goal of the reproductive behaviour is to achieve (proceptive) or avoid (contraceptive) a pregnancy. According to the TDIB, intentions are assumed to incorporate the perception of the desires of significant others, above all the partner; as well as other situational factors that may prevent individuals from simply what they want to do. Unlike the TPB, the TDIB explicitly considers the dyadic nature of reproduction (Miller and Pasta 1996) and the interaction between the partners at each stage of the sequence (Miller et al. 2004).

Miller and Pasta (1996) identified two main components of the disagreement between the partners, each of which influences the individual's decision-making differently. The signed difference or influence effect, which depends on which member of the couple has more or less influence on the behaviour; and the absolute difference or conflict effect, which is independent of the desires of the male or the female partner. The conflict effects produce a delay in fertility decision-making due to inertia, which tends to favour the partner who does not want to have a child in a context in which using contraception between births is standard practice (Davidson and Beach 1981; Beach et al. 1982). The influence effect may also produce a delay in fertility if a veto-power model is working within the couple (Thomson 1997; Thomson and Hoem 1998; Voas 2003), which also requires that the two partners concur in their views before the action is taken (in this case, a proceptive behaviour).

\section{Couple Conflict and Decision Rules}

One important criterion in the resolution of conflict is the predominant decision rule being used by the couple. In the following, we will provide an overview of the four decision rules that may be applied by couples seeking to resolve this conflict.

If the two partners differ in their child number or child-timing intentions, they try to reach a decision that could be mid-way between the preferences of the two (Thomson 1997; Thomson and Hoem 1998; Thomson et al. 1990; Jansen and Liefbroer 2006). The corresponding decision rule is called the golden mean rule: partners view each other's intentions as equally important, and, since they each have equal power in the negotiations, they will try to strike an acceptable compromise which equally reflects their initial desires. Jansen and Liefbroer (2006) found that this is the most frequent heuristics approach used by couples in the Netherlands. Studies by Thomson (1997) and Thomson and Hoem (1998) produced similar results for the USA and Sweden. There are however, other decision rules that can be adopted by couples with conflicting attitudes toward childbearing. The first is the power rule, according to which the partner who has greater access to socioeconomic resources 
will prevail. As long as men have higher occupational and income levels than women, they will predominate in the couple's negotiation process. Male prevalence is also assumed under the "patriarchal" rule. A second heuristic is the sphere of interest rule, according to which the partner in whose sphere of interest a decision is located will have greater influence over subsequent behavior. As long as childbearing tends to lie in the female sphere of interest, women may be considered more influential in the couple's fertility decision-making. A third option is the social drift rule, according to which the maintenance of the status quo will prevail by favoring the partner who does not want to have children if the use of contraception between births is routine. Neal and Groat (1980) demonstrated that women who perceive their broader environment as being unpredictable develop a lifestyle characterized by social drift, and they respond to events like pregnancy as they happen, rather than deliberately causing them to happen through an effort of their own. Jansen and Liefbroer (2006) argued that, in the Netherlands, this rule controls couples' reproductive choices if neither of the partners has a clear intent to impose her/his own point of view on the other.

In this paper, we analyze Italian data. Italy is a country chatacterized by a late transition to adulthood and persistently low fertility levels (below 1.4 since the mid-1980s) (Tomassini et al. 2003; Morgan 2003; De Rose et al. 2008; Caltabiano et al. 2009). The family formation process is characterized by the presence of strong intergenerational ties, which are reinforced by the familistic Italian welfare system (Saraceno 1994; Dalla Zuanna and Micheli 2004). Indeed, since the levels of public support of families with young children and public provision of childcare services are low, most young Italian dual-earner couples rely heavily on the help of their parents (especially their mothers) in raising their children. In addition, the prevalence of a male bredwinner model is combined with a low level of gender equity and low rates of female labor force participation. According to the European Union Labour Force Survey data, the inactivity rates of women aged 25-54 ranged in 2011 from less than $15 \%$ in Slovenia and Sweden to more than $35 \%$ in Italy.

Family responsibilities are the main reason for inactivity (OECD 2006). Women who participate in the labor market face significant challenges in combining work and family (Pinnelli 1995; Del Boca et al. 2004).

Italian literature on the negotiation of fertility choices within couples is scarce. A recent analysis on the determinants of couple disagreement about childbearing intentions suggested that women in more egalitarian relationships-i.e., those who cohabit and those who are employed - are more likely to voice their disagreement if their partner wants a first or a second child (Rosina and Testa 2009; Cavalli 2010; Cavalli and Rosina 2011).

\section{Research Hypotheses}

In tradition-bound Italian society, which is characterized by a low degree of gender equity at the individual and societal levels, women are primarily responsible for childcare and childrearing activities. Thus, couples and society as a whole may consider it fair for the woman's view to predominate. We advanced a first working hypothesis as follows: Women 
have more influence on childbearing behavior if there is a conflict with their partners about having a (nother) child in the next three years (Hypothesis 1, the decision generally follows the sphere of influence rule).

We may also expect that, when gender roles are more symmetric, the partners will tend to have an equal amount of power in the negotiation process. Hence, we suppose that: Partners have the same degree of influence on childbearing decisions if they share housework and childcare duties equally (Hypothesis 2, gender equality favors the adoption of the golden mean decision rule).

In Italy, as in other contemporary societies, the intra-household distribution of bargaining power in dual-earner couples has become an important factor driving the fertility decisions of spouses with different interests (Jansen and Liefbroer 2006). Hence, we express our third research hypothesis as follows: Partners have the same degree of influence on childbearing decisions if they have the same level of bargaining power (Hypotesis 3, equal bargaining power favors the adoption of the golden mean decision rule).

As an alternative to the sphere of influence rule, we might expect to find that the partner who has more access to socioeconomic resources drives the negotiation process in the event of a conflict. This may be the case especially at higher parities, as the decision about whether to have an additional child may be affected by financial considerations (Becker 1981, De Santis 2004). Thus, we formulated our fourth research hypothesis as follows: Men have more power than women in childbearing decisions if the male breadwinner model is adopted by the couple (Hypothesis $\mathbf{4}$, the power decision rule).

Italy is characterized by low levels of financial support for families with children and a lack of adequate policy measures to facilitate the balancing of work and family life (such as access to parental leave, childcare, and part-time employment). In such a context, childbearing is seen as a potential threat to the achieved standard of living. Because having a baby has immediate and permanent implications for individuals, both partners must consent (or have veto power) (Rindfuss et al. 1988). Moreover, as in other modern societies, the use of contraception between births is the prevalent regime in Italy. Thus, due to the inertia mechanism, conceiving a child requires a change in the standard behavior of a couples, and automatically favors the partner who does not want to have a child (Davidson and Beach 1981). It should be noted that veto power and inertia work via different mechanisms, but produce similar inhibiting effects on childbearing in contexts characterized by almost universal contraception among couples. We advanced our fifth research hypothesis as follows: Partners who disagree about wanting a(nother) child in the next three years are more likely to not have a child than to have a child in the subsequent three-year period (Hypothesis 5, veto power effect). 


\section{Data}

We used data from the Multipurpose Household Survey on "Family and Social Subjects," which was carried out by the Italian National Institute of Statistics (Istat) between 2003 and 2007. As the survey unit is the household, information on both members of the couple is available. The follow-up wave includes 10,000 individuals who were randomly drawn from the initial sample of 50,000 respondents interviewed at the initial wave.

The survey was addressed to people aged 18-64, but the questions on fertility intentions were only asked to respondents aged 18-49. Within this age group, we restricted the analytic sample to couples in which both partners provided answers to the fertility intentions questions at the initial survey (non-responses were 4\%), and at least one of the two provided information about the events experienced by the couple between the two waves (2003-2007). If only one of the partners was followed up (which affected $60 \%$ of the couples interviewed in 2003), we checked for the possibility that she/he experienced a partnership disruption in the inter-survey period. This was the case for $1 \%$ of the respondents re-interviewed in 2007 without their partners. These cases were taken out from the analysis, because if a birth occurred in the inter-survey period, we could not determine whether this happened in the framework of the old or a new relationship. Our final analytic sample included 2,304 couples for whom we could compare the fertility intentions as reported at the first wave with the subsequent reproductive behavior as measured at the second wave.

The people interviewed in 2003 had been required to indicate their short-term fertility intentions by answering the following question: "Do you intend to have a child in the next three years?" The response options were: "definitely not," "probably not," "probably yes," and "definitely yes." The people re-interviewed in 2007 were asked whether they had had a child in the inter-survey period, and whether the child was biological, affiliated, or adopted. The survey questions were: "From November 2003 up to now have you had a child?" and "From November 2003 up to now have you adopted a child?" Information on the reproductive history, including the precise date of each birth as well as the sex of each newborn, were also asked in the questionnaire.

Exactly the same questions were addressed to both partners, which allows us to conduct a fully comparative analysis of the responses. Moreover, all of the fertility intentions items were included in the self-administered questionnaires and this ensures a high degree of independence in the answers of the partners. We did not find any systematic differences in the responses given by the male and female partners, with both the men and the women using the given response options in the same ways to express the strength of their childbearing plans.

Some additional questions on fertility intentions were asked in 2003: "In the future do you intend to have any child?" and "How many children would you like to have over your life course?" The women and men re-interviewed in 2007 were asked again the entire set of fertility intentions questions: "Do you intend to have a (nother) child in the next three years?", "In the future do you intend to have a(nother) child?", and "How many children would you like to have over your life course?" 
We defined couple disagreement as opposing responses; i.e.; to have a child or not to have a child in the next three years, regardless of whether the respondent said definitely or probably (Scheme 1).

Scheme 1 Definition of couple disagreement. Answers to the item: "Do you intend to have a child in the next three years?"

\begin{tabular}{|c|c|c|c|c|}
\hline Woman & Definitely not & Probably not & Probably yes & Certainly yes \\
\hline Definitely not & \multirow{2}{*}{\multicolumn{2}{|c|}{ both no }} & \multirow{2}{*}{\multicolumn{2}{|c|}{ M yes, W no }} \\
\hline Probably not & & & & \\
\hline Probably yes & \multicolumn{2}{|c|}{ M no, W yes } & \multicolumn{2}{|c|}{ both yes } \\
\hline
\end{tabular}

\section{Model and Variables}

We estimated logistic regression models with a response variable equal to one if the couple had had at least one child in the inter-survey period, and zero otherwise. All of the models were stratified by parity, which is in line with a conditional-sequential fertility decision-making process (Namboodiri 1972; Bulatao 1981). Specifically, separate models were run on childless couples, couples with only one child, and couples with two or more children.

The key explanatory variable in the models was the combined partners' intentions to have a(nother) child in the next three years. According to the definition adopted, agreement consisted of partners giving the same answer, either positive or negative, irrespective of whether they indicated "probably" or "certainly." We computed the following four-categorical variable: "both partners do not want;" "man wants, woman does not want;" "man does not want, woman wants;" and "both partners want." For the sake of simplicity, in Scheme 1 and in the tables showing the empirical results, we labeled the above mentioned categories as follows: "both no," "M yes, W no," "M no, W yes," "both yes."

The covariates included in the models are as follows: the type of union, the man's and the woman's education, the man's and the woman's employment status, the man's and the woman's age, the man's and the woman's attendance at religious services, the difference in the levels of education between the partners, the woman's satisfaction with her partner's involvement in housework and childcare duties, the partners' bargaining power, and the geographical area of residence. The distribution of the variables used in the multivariate analysis is reported in Table 1.

We measured men's involvement in childcare tasks with a three-category variable. We contrasted women who indicated they were very satisfied with their partner's involvement in housework and family duties with women who were quite satisfied and women who were not at all satisfied. The question item, which was posed only to women, was worded as follows: 
"How satisfied are you with the division of housework and family duties between you and your partner?" This measure could be also interpreted as a proxy for the quality of the relationship, which has also been found to be highly relevant for childbearing behaviour (Rijken and Liefbroer 2009; Rijken and Thomson 2010).

We measured the intra-household distribution of bargaining power by the difference in educational levels between the partners (Lundberg and Pollak 1996). The variable had three categories: the man is better educated than the woman, the man and the woman have the same levels of education, and the woman is better educated than the man. One of the two partners was considered to be better educated if the achieved level of education was higher than that of the partner's, regardless of the size of the gap between the two education levels. A refinement of the variable that took into account the size of this gap was not introduced because the sample sizes were too small. We also tried a different proxy variable: the woman's perception regarding which of the partners has more decision-making power on children's education (the item was worded as follows: "Which of the partners has more power in decidion-making on the following issues?" The response options were: "he has more "" she has more," "she and he have equal power," and "it is not relevant"). We could not find any significant difference in the results by using this alternative variable. For this reason, we decided to only show results in which the bargaining power was measured by the difference in the levels of education between the partners. 
Table 1 Distribution of variables used in the analysis (Values in percentage)

\begin{tabular}{|c|c|c|c|}
\hline & $\begin{array}{l}\text { Childless } \\
\text { Couples } \\
\end{array}$ & $\begin{array}{c}\text { Couples with one } \\
\text { child } \\
\end{array}$ & $\begin{array}{l}\text { Couples with two } \\
\text { or more children } \\
\end{array}$ \\
\hline \multicolumn{4}{|l|}{ Partners' combined fertility intentions } \\
\hline Both partners yes & 70 & 36 & \\
\hline Man yes, Woman no & 4 & 6 & \\
\hline Man no, Woman yes & 5 & 4 & \\
\hline Both partners no & 21 & 54 & 91 \\
\hline \multicolumn{4}{|l|}{ Geographical area of residence } \\
\hline North & 56 & 57 & 42 \\
\hline Centre & 17 & 18 & 18 \\
\hline South and Islands & 26 & 24 & 41 \\
\hline \multicolumn{4}{|l|}{ Level of education } \\
\hline Woman with low education (Isced $0-2$ ) & 24 & 31 & 42 \\
\hline Woman with medium education (Isced 3 - 4) & 55 & 55 & 47 \\
\hline Woman with high education (Isced 5 - 6) & 21 & 14 & 11 \\
\hline Man with low education (Isced 0 - 2) & 38 & 42 & 45 \\
\hline Man with medium education (Isced 3 - 4) & 45 & 45 & 44 \\
\hline Man with high education (Isced 5 - 6) & 16 & 14 & 11 \\
\hline \multicolumn{4}{|l|}{ Partnership Status } \\
\hline Married & 89 & 96 & 99 \\
\hline Cohabiting & 11 & 4 & \\
\hline \multicolumn{4}{|l|}{ Attendance at religious services } \\
\hline Woman attends & 46 & 55 & 68 \\
\hline Woman does not attend & 54 & 45 & 32 \\
\hline Man attends & 36 & 42 & 50 \\
\hline Man does not attend & 64 & 58 & 50 \\
\hline \multicolumn{4}{|l|}{ Employment status } \\
\hline Woman employed & 77 & 67 & 58 \\
\hline Woman unemployed & 17 & 22 & 35 \\
\hline Woman enrolled in education & 5 & 11 & 7 \\
\hline Man employed & 97 & 98 & 97 \\
\hline Man unemployed & 2 & 1 & \\
\hline Man enrolled in education & 1 & 1 & 1 \\
\hline \multicolumn{4}{|l|}{ Gender equality } \\
\hline Woman very satisfied with division of tasks & 26 & 33 & 49 \\
\hline Woman is quite satisfied with division of tasks & 25 & 20 & 24 \\
\hline Woman dissatisfied & 49 & 47 & 27 \\
\hline \multicolumn{4}{|l|}{ Bargaining power } \\
\hline Woman and man with same educational level & 56 & 58 & 61 \\
\hline Woman and man with different educational & 44 & 42 & 39 \\
\hline $\mathrm{N}$ cases & 287 & 655 & 1362 \\
\hline
\end{tabular}




\section{Results}

\subsection{Descriptive Analysis}

The percentage of couples who were found to disagree was slightly less than $10 \%$, and it was evenly divided between the cases in which only the female partner wanted a child, and the cases in which only the male partner wanted a child, regardless of whether the couples had already had a child at the time of the first wave (see also Testa et al. 2011). In Figure 1, the percentages of couples who had a child between 2003 and 2007 by partners' intentions, as reported in 2003, are given separately for childless couples, couples with only one child, and couples with two or more children. At parity zero, the share of couples who had a child between the two waves gradually increased from $8 \%$ if the partners agreed on not having a child, to $55 \%$ if the partners agreed on having a child. Meanwhile, the couples who disagreed took an intermediate position: $27 \%$ and $43 \%$ had a child if only the male partner or only the female partner, respectively, wanted to have a first one. Interestingly, couples in which only the male partner wanted a child were closer in terms of reproductive behavior to those who agreed on not having a (first) child than to those who agreed on having a (first) child, while couples in which only the female partner wanted a child were closer to agreement on yes than to agreement on no. At parity one, the percentage of couples who had a child between 2003 and 2007 went from 5\% if the partners had agreed on not having a second child three years previously, to $54 \%$ if the partners had agreed on having a second child in 2003 . Unlike for childless couples, the share of childbearing was quite similar in the two signed categories in which only the woman or only the man wanted a child: $31 \%$ of the disagreeing couples had a second child if only the male partner wanted the child, and $34 \%$ of the disagreeing couples had a second child if only the female partner wanted the child. At parity two or above, 3\% of couples had another child if the partners agreed on not wanting the child or if only the male partner wanted the child, $49 \%$ had another child if the partners agreed on having the child, and $15 \%$ of couples had another child if only the woman wanted the child (Figure 1). Unlike for parities zero and one, the childbearing outcome of disagreement shifted more toward not having a child than toward having a child, especially if only the male partner wanted the child. 
Figure 1 Share of couples having a child between 2003 and 2007 by partners' intentions to have a(nother) child in the next three years and couple's parity in 2003

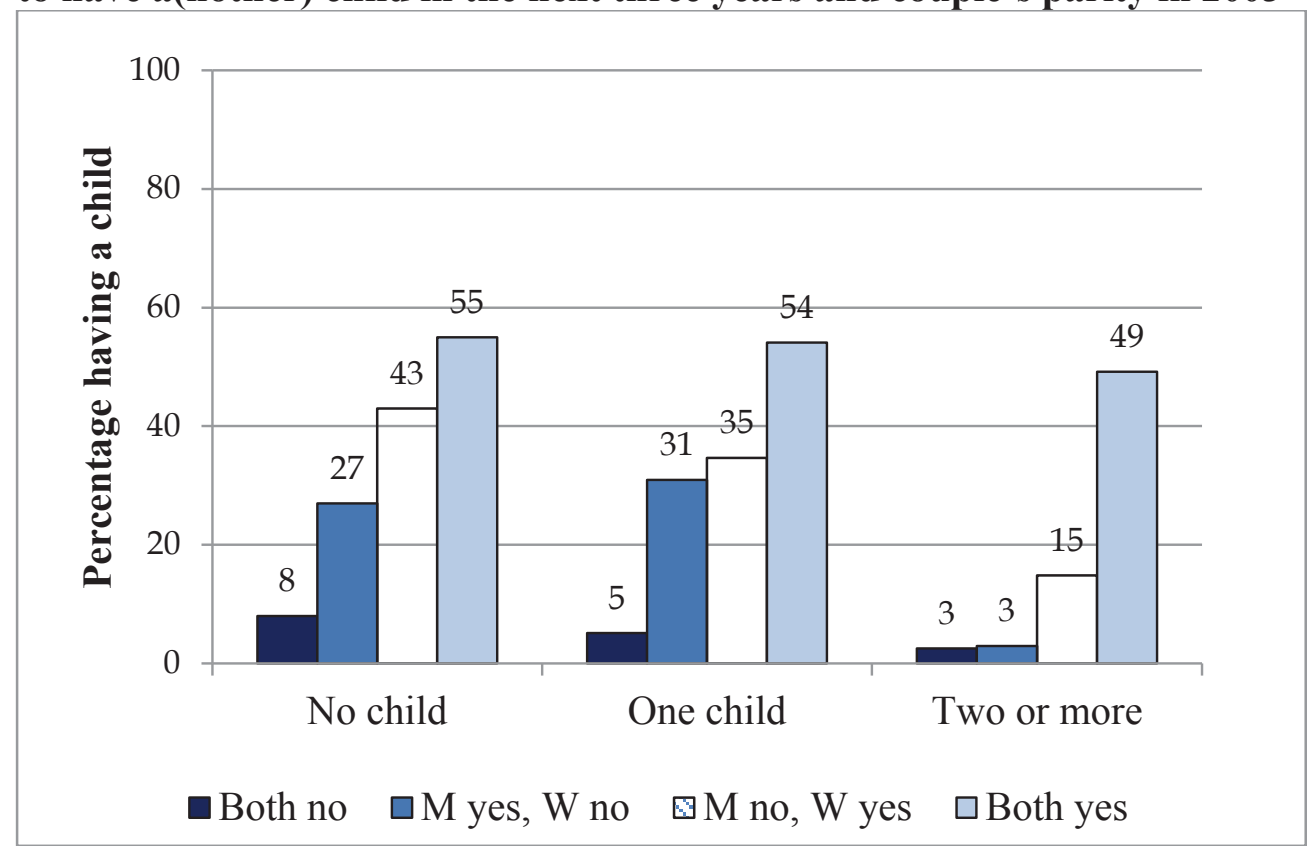

\subsection{Multivariate Analysis}

In Table 2, we report the estimates of the logistic regression models on the probability of having a child in the three years after the first wave. Before moving on to the description of the findings related to our main hypotheses, we will comment on the effects of the demographic and socioeconomic variables included in the models. Besides age and geographical area, which are usually included as control variables, education, employment, and partnership status are the explanatory variables typically considered as relevant determinants of reproductive decisions. Having a high level of education and being employed have been found to be positively associated with the likelihood of realizing previously stated fertility intentions in France and Italy (Toulemon and Testa 2005; Rinesi 2009). The results may, however, vary across different countries. For example, Quesnel-Vallée and Morgan (2003) found that women who have a degree have fewer desired children than their less educated counterparts in the United States. Several studies have also shown that marital status plays an important role in childbearing (Noack and Østby, 2002; Quesnel-Vallée and Morgan 2003; Berrington 2004; Testa and Toulemon 2006). Cohabiting has been found to have a depressing effect on the probability of realizing previously stated fertility intentions in the U.S. (Schoen et al. 1999), but Toulemon and Testa (2005) found no statistically significant effect of cohabiting on the likelihood of realizing the intention to have a first child in France.

In our analysis, a positive effect of education, especially at parities zero and two or above, has been detected, all other things being equal. This result may be related to the prevalence of the income effect (related to the high wages levels of highly educated women) over the substitution effect (foregone wages due to the time taken off from work to raise 
children). For couples with only one child, the probability of having a second one (usually considered the normative target) was shown to be significantly and positively influenced by the man's employment status. By contrast, a woman's employment status was relevant only for the entry into parenthood. As expected, the progression to a first child was found to be less likely among cohabiting couples, but afterwards, cohabiting did not have any statistical significant effect on the likelihood of having a child. Finally, in contrast to our expectations, a woman's level of satisfaction about her partner's involvement in housework and childcare duties had only a negligible effect on the likelihood of having a child in the inter-survey period. Couples in which the woman was dissatisfied had a lower probability of having a(nother) child; but, all other things being equal, the negative effect was not significant (see Table 2). 
Table 2 Beta coefficients from the logistic regression model on having a child between 2003 and 2007

\begin{tabular}{|c|c|c|c|c|c|c|}
\hline & Childless & & One child & & Two children & \\
\hline \multicolumn{7}{|l|}{ Partners' fertility intentions } \\
\hline Both yes & 2.13 & $* * *$ & 2.16 & $* * *$ & 3.28 & $* * *$ \\
\hline M yes, W no & 1.25 & & 1.17 & $* * *$ & -0.27 & \\
\hline M no, W yes & 1.50 & $* *$ & 1.29 & $* * *$ & 1.35 & $* *$ \\
\hline \multicolumn{7}{|l|}{ Both no (ref.) } \\
\hline \multicolumn{7}{|l|}{ Age } \\
\hline Woman aged 38 or younger & -0.06 & & -0.13 & $* * *$ & -0.04 & \\
\hline Man aged 42 or younger & -0.09 & & -0.10 & $* * *$ & -0.12 & $* *$ \\
\hline \multicolumn{7}{|l|}{ Geographical area } \\
\hline North & 0.23 & & -0.11 & & -0.26 & \\
\hline \multicolumn{7}{|l|}{ Centre (ref.) } \\
\hline South Islands & 0.36 & & -0.12 & & -0.57 & \\
\hline \multicolumn{7}{|l|}{ Education } \\
\hline \multicolumn{7}{|l|}{ Female partner } \\
\hline Low (Isced 0 - 2) & -0.50 & & -0.20 & & 0.46 & \\
\hline \multicolumn{7}{|l|}{ Medium (Isced 3 - ref.) } \\
\hline High (Isced $5-6$ ) & 0.91 & $* *$ & -0.25 & & 0.86 & $* *$ \\
\hline \multicolumn{7}{|l|}{ Male partner } \\
\hline Low (Isced 0 - 2) & -0.04 & & -0.34 & & -0.68 & $* *$ \\
\hline \multicolumn{7}{|l|}{ Medium (Isced 3 - ref.) } \\
\hline High (Isced $5-6$ ) & 0.33 & & 0.37 & & 0.28 & \\
\hline \multicolumn{7}{|l|}{ Partnership status } \\
\hline \multicolumn{7}{|l|}{ Married (ref.) } \\
\hline Cohabitation & -1.01 & $* *$ & 0.29 & & 1.29 & \\
\hline \multicolumn{7}{|c|}{ Attendance at religious services } \\
\hline \multicolumn{7}{|c|}{ Female partner } \\
\hline \multicolumn{7}{|l|}{ Does not attend (ref.) } \\
\hline Does attend & 0.13 & & -0.16 & & 0.39 & \\
\hline \multicolumn{7}{|l|}{ Male partner } \\
\hline \multicolumn{7}{|l|}{ Does not attend (ref.) } \\
\hline Does attend & 0.19 & & 0.06 & & -0.03 & \\
\hline \multicolumn{7}{|l|}{ Employment status } \\
\hline \multicolumn{7}{|l|}{ Female partner } \\
\hline \multicolumn{7}{|l|}{ Not employed (ref.) } \\
\hline Employed & 3.18 & $*$ & -0.16 & & -0.13 & \\
\hline Enrolled in education & 2.37 & & -0.09 & & 0.06 & \\
\hline \multicolumn{7}{|l|}{ Male partner } \\
\hline \multicolumn{7}{|l|}{ Not employed (ref.) } \\
\hline Employed & 0.87 & & 2.54 & $* * *$ & 0.69 & \\
\hline Enrolled in education & 0.45 & & -2.05 & $*$ & -0.15 & \\
\hline \multicolumn{7}{|l|}{ Gender equality } \\
\hline Woman very satisfied & -0.04 & & -0.16 & & -0.12 & \\
\hline Woman quite satisfied (ref.) & & & & & & \\
\hline Woman unsatisfied & -0.01 & & -0.50 & & -0.22 & \\
\hline
\end{tabular}


In order to determine whether one of the partners prevailed in the final decision, we checked whether the effect of disagreement was absolute or signed. With this aim in mind, we estimated a model in which the categories "only she" and "only he" wanted a(nother) child were considered separately (Table 3, Model I for signed disagreement), and compared it with a model in which only one disagreement category was included (Table 3, Model II for absolute disagreement). Model I suggests that the probability of having a child was higher if only the woman wanted to have a child than if only the man wanted to have a child, which would appear to indicate that the woman prevailed in fertility decisions at all parities. However, at parities zero and one, the differences between the two coefficients were quite small in terms of magnitude, and were not statistically significant, according to the findings of the tests on the homogeneity between the two signed-disagreement coefficients (Table 4). Hence, the empirical evidence for childless couples or couples with only one child indicates that the disagreement effect was absolute; i.e., it did not depend on whether only the female or the male partner wanted to have a child. At parities two or above, the differences between the two signed disagreement coefficients were bigger (Table 3, Model I last column), and the hypothesis on the equality of the two disagreement coefficients could be rejected (Table 4, last row). This allows us to infer that the disagreement was signed, and that women were more influential than the men in childbearing decisions at parity two or above. Consistently, in the models in which the two categories "man yes, woman no" and "man no, woman yes" were collapsed into a single variable (Table 3, Model II), the size of the absolute disagreement coefficient was somewhere between that of "both yes" and that of "both no" at parities zero and one; while it was closer to "both no" than to "both yes" at parities two or above, among which the likelihood of having another child was strongly precluded if the woman vetoed this decision.

\subsection{Absolute versus Signed Effect of Disagreement}

In order to determine whether one of the partners prevailed in the final decision, we checked whether the effect of disagreement was absolute or signed. With this aim in mind, we estimated a model in which the categories "only she" and "only he" wanted a(nother) child were considered separately (Table 3, Model I for signed disagreement), and compared it with a model in which only one disagreement category was included (Table 3, Model II for absolute disagreement). Model I suggests that the probability of having a child was higher if only the woman wanted to have a child than if only the man wanted to have a child, which would appear to indicate that the woman prevailed in fertility decisions at all parities. However, at parities zero and one, the differences between the two coefficients were quite small in terms of magnitude, and were not statistically significant, according to the findings of the tests on the homogeneity between the two signed-disagreement coefficients (Table 4). Hence, the empirical evidence for childless couples or couples with only one child indicates that the disagreement effect was absolute; i.e., it did not depend on whether only the female or the male partner wanted to have a child. At parities two or above, the differences between the two signed disagreement coefficients were bigger (Table 3, Model I last column), and the hypothesis on the equality of the two disagreement coefficients could be rejected (Table 4, last row). This allows us to infer that the disagreement was signed, and that women were more 
influential than the men in childbearing decisions at parity two or above. Consistently, in the models in which the two categories "man yes, woman no" and "man no, woman yes" were collapsed into a single variable (Table 3, Model II), the size of the absolute disagreement coefficient was somewhere between that of "both yes" and that of "both no" at parities zero and one; while it was closer to "both no" than to "both yes" at parities two or above, among which the likelihood of having another child was strongly precluded if the woman vetoed this decision.

Table 3 Testing absolute versus signed effect of disagreement. Beta coefficients from the logistic regression model on having a child in the three years after the first wave (2003)

\begin{tabular}{llcr}
\hline & Childless & One child & $\begin{array}{c}\text { Two or more } \\
\text { children }\end{array}$ \\
\hline Model I & & & \\
\hline Both yes & $2.13^{* * *}$ & $2.16^{* * *}$ & $3.28^{* * *}$ \\
M yes, W no & $1.25^{* *}$ & $1.17^{* *}$ & -0.27 \\
M no, W yes & $1.50^{* *}$ & $1.29^{* *}$ & $1.35^{* *}$ \\
Both no (ref.) & & & \\
\hline
\end{tabular}

\begin{tabular}{llll}
\hline Model II & & & \\
\hline Both yes & $2.13^{* * *}$ & $2.16^{* * *}$ & $3.27^{* * *}$ \\
Absolute disagreement & $1.40^{* *}$ & $1.22^{* * *}$ & $0.78^{*}$ \\
Both no (ref.) & & & \\
\hline
\end{tabular}

$(\dagger \mathrm{p}<.10 ; * \mathrm{p}<.05 ; * * \mathrm{p}<.01 ; * * * \mathrm{p}<.001)$.

${ }^{a}$ Models controlled for all the variables shown in Table 2.

Table 4 Results of the tests on the equality of the coefficients on partners' combined short-term fertility intentions

\begin{tabular}{lll}
\hline & Test on the beta coefficients ${ }^{\text {a }}$ & Results \\
\hline Parity 0 & M yes, $\mathrm{W}$ no $=\mathrm{M}$ no, $\mathrm{W}$ yes & Not rejected \\
\hline Parity 1 & M yes, $\mathrm{W}$ no $=\mathrm{M}$ no, W yes & Not rejected \\
\hline Parity 2+ & M yes, $\mathrm{W}$ no $=\mathrm{M}$ no, $\mathrm{W}$ yes & Rejected \\
\hline
\end{tabular}

${ }^{\mathrm{a}}$ Beta coefficients from the Model I shown in Table 3.

\subsection{Veto Power and Disagreement}

In order to evaluate whether disagreement was shifted more towards agreement on having a(nother) child than towards agreement on not having a(nother) child, we compared the fit of a model with a linear specification of both partners' fertility intentions in which disagreement had a score midway between agreement on yes and agreement on no, with that 
of a model in which a categorical variable (N-1 dummies) reflected the possible combinations of partners' short-term childbearing intentions. The linear variable for the partners' intentions took the value zero for agreement on no, one for disagreement, and two for agreement on yes (Table 5). We did not find empirical evidence that the models with the categorical variable fit the data better than the models with a linear specification of partners' combined intentions, which supports the hypothesis that disagreement produces a middle childbearing outcome between that of agreement on yes and that of agreement on no. This analysis was developed only on childless couples and couples with one child, as the previous results showed that disagreement was signed and shifted more towards agreement on no than towards agreement on yes if only the man wanted to have another child at parity two or above.

Table 5 Testing the linear effect of disagreement. Beta coefficients from the logistic regression model on having a child in the three years after the first wave (2003)

Model I

Childless One child

\begin{tabular}{|c|c|c|}
\hline $\begin{array}{l}\text { Linear specification of partners' } \\
\text { intentions }\end{array}$ & $1.01 * * *$ & $1.07 * * *$ \\
\hline Log-likelihood & -146.09 & -239.00 \\
\hline AIC- BIC & 328.18394 .04 & $514.00 \quad 594.72$ \\
\hline
\end{tabular}

\begin{tabular}{lll}
\hline Model II & & \\
\hline Both yes & $2.13^{* * *}$ & $2.16^{* * *}$ \\
Absolute disagreement & $1.39^{* *}$ & $1.21^{* * *}$ \\
Both no (ref.) & & \\
\hline
\end{tabular}

Log-likelihood $\quad-145.89 \quad-238.19$

\begin{tabular}{|c|c|c|}
\hline AIC-BIC & $329.80 \quad 399.33$ & \\
\hline
\end{tabular}

$(\dagger \mathrm{p}<.10 ; * \mathrm{p}<.05 ; * * \mathrm{p}<.01 ; * * * \mathrm{p}<.001)$

${ }^{a}$ Models controlled for all the variables shown in Table 2.

\subsection{Gender Equality and Disagreement}

We expected to find that gender equality in reproductive decision-making increases in relationships in which men and women share equal bargaining power. To test this research hypothesis, we compared two different models: one in which an interaction effect between disagreement and an equal level of education between men and women (proxy for equal bargaining power) was included, and one in which such an interaction was left out. The empirical evidence favoured the latter model, which suggests that couples in which the partners had the same power in decision-making were not necessarily more egalitarian in terms of childbearing decisions than couples in which the distribution of bargaining power was gendered. 
We expected to find that gender equality in reproductive decision-making would be turned into the prevalence of the male partner if the male breadwinner model was adopted within the couple. To test this research hypothesis, we compared the fit of a model in which an interaction variable between disagreement and the dichotomous variable for the presence of a male breadwinner model was included with a model in which the above-mentioned interaction was left out. The latter model fitted the data better than the former (the interaction effect was not significant), which suggests that the man's influence on childbearing decisions did not increase in couples in which the man had more access to economic resources than the woman (results are not shown but are available upon request).

\section{Summary and Concluding Remarks}

In this analysis, we compared prospective short-term childbearing intentions with subsequent reproductive behaviour by using couple longitudinal data in order to determine whether one of the partners has more decision-making power when the partners disagree. This topic is generating a growing amount of interest among academic researchers, but it is underinvestigated because high-quality data on both partners are needed, and data of this kind are not easy to collect. Our study design was particularly suitable for this aim because it reflects a genuine couple approach in a longitudinal perspective.

We found that if a conflict arises within the couple about having a(nother) child, there is no gender prevalence in the final decision, and that the effect of disagreement in terms of childbearing outcomes lies between that of agreement on yes and that of agreement on not having a(nother) child. This evidence is in line with the findings of other studies in which the same issue has been investigated in different countries, like Germany (Bauer and Kneip 2012), the Netherlands (Jansen and Liefbroer 2006), Sweden (Thomson and Hoem 1998), and the U.S. (Thomson et al. 1990; Thomson 1997). Unlike the latter two studies mentioned above, however, the Italian GGS did not support the existence of a symmetrical double veto power model. Only the female partner was found to have a veto position, and only at parities two or above; i.e., when the decision was to move beyond the widely accepted two-child family size norm.

The Italian GGS data did not support the hypotheses that gender equality in fertility decision-making is driven by the equal division of housework and childcare tasks and the equal distribution of bargaining power between partners. These results confirm earlier studies in which the equality of the partners in childbearing decisions was proved to be independent of the gender egalitarian arrangements within the couple (Thomson and Hoem 1998). This finding could, however, be due to the very rough measures of gender equality used in the analysis of the Italian case: gender equality was measured by a woman's perception of her partner's contributions to the housework and childcare tasks, and the distribution of bargaining power was based on the difference in the levels of completed education between the partners. Recent research has shown that women's bargaining power depends on a series of variables (Bertocchi et al. 2012). It is therefore possible that more refined measures would produce different results. 
The main hypothesis that women are dominant in fertility decision-making because childbearing mainly lies in their sphere of influence, which was advanced in an earlier study on Italy (Testa et al. 2011) and verified in earlier research on other countries (Townes et al. 1980; Fried et al. 1980; Beckman 1984; Rindfuss et al. 1988), could not be supported in the current analysis. Although the outcomes of couples in which only the female partner wanted a(nother) child were, compared to the outcomes of couples in which only the male partner wanted a(nother) child, closer to yes than to no, the two types of disagreement were not statistically different. This suggests that, for lower parities, women in Italy are not necessarily more influential than men in reproductive decision-making. This gender symmetry was found despite the lack of gender equality and the low level of public support for families in Italy, which means that women are primarily responsible for childrearing. Our interpretation of this result is that, because childbearing has long-term implications for both partners, neither of them is willing to have a child without the consent of the other partner. Thus, the failure to reach an agreement with the partner may constitute an important reason why the stated fertility intentions do not correspond to subsequent fertility outcomes.

The results are in line with the assumption that models based on both partners' fertility intentions are superior to those based on only one partner's intentions (Fried and Udry 1979; Fried et al. 1980; Morgan 1985), and that models exclusively based on women's intentions are likely to be miss-specified (Corijn et al. 1996).

An important caveat inherent to the data has to do with measurement issues: reported child-timing intentions might reflect the resolution of a negotiation process between partners, as the theory on fertility decision-making (Ajzen 1991; Miller 1994; Miller 2011b) and some empirical findings (Barret and Wellings 2002) would suggest. If this is the case, concurring responses from both partners would not rule out the presence of disagreement; or alternatively, an apparent disagreement between the partners might happen by chance, because only one of the two respondents incorporated the partner's view in his or her answer. Although this is a general challenge in the analysis of couple data (Becker 1996), we believe intentions may not be the most important element in the dynamics of couple interactions. In order to gain a better understanding of the partners' negotiation process, we may want to also look at the desires and motivations expressed at earlier stages of the fertility decision-making sequence. Ideally, the information on contraceptive behavior would complement the data on partners' fertility motivations, desires, and intentions. Similarly, the information on the perception of the partner's fertility intentions should complement the data on the objective partner's fertility intentions. A comparison of these data would allow us to discern whether each of the partners is incorporating the partner context into his/her own intentions, and if so, the extent to which he/she does so (Testa 2010 and 2012a). This approach has already been used in an earlier study (Morgan 1985). In this analysis, we checked whether the partners' short-term fertility intentions were correlated each other, and we found a Pearson's correlation coefficient of 0.8 at parity zero and one and of 0.6 at higher parities. These values seem to support the idea that the measure of the intention to have a(nother) child is the result either of a spousal bargaining process (Fisher 2000) or of assortative mating on the partner market, in which individuals tend to choose partners who have similar fertility preferences. The extent to which these two phenomena may influence the findings on the equality between partners in their fertility 
decision-making cannot be investigated with the data at hand, but represents an interesting field of analsyis for future research. 


\section{References}

Ajzen, I. (1991). The Theory of Planned Behavior. Organizational Behavior and Human Decision Processes, 50: 179-211.

Ajzen, I. (2010). Fertility intentions and the Theory of Planned Behaviour. Paper presented at the International Conference on Reproductive Decision-making in a Macro-Micro Perspective, Vienna, December 2-3, 2010.

Barret, G. \& Wellings, K. (2002). What is a "planned" pregnancy? Empirical data from a British study. Social Science \& Medicine, 55: 545-557.

Bauer, G. \& Kneip, T. (2012). Fertility from a couple perspective: a test of competing decision rules on proceptive behaviour. European Sociological Review: 1-14.

Beach, L.R., Hope, B.D., \& Campbell, F.L. (1982). The expectation-threshold model of reproductive decision making. Population and Environment, 5(2), 95-108. doi:10.1007/BF01367489.

Beckman, L., R. Aizenberg, A.B. Forsythe \& Day, T. (1983). A theoretical analysis of antecedents of young couples' fertility decisions and outcomes. Demography, 20(4), 519-533.

Beckman, L.J. (1984). Husbands' and wives' relative influence on fertility decisions and outcomes. Population and Environment: Behavioral and Social Issues, 7: 182-197.

Becker, G. S. (1981). A Treatise on the Family. Cambridge, MA. Harvard University Press.

Becker, G.S. (1996). Couples and reproductive health: a review of couple studies. Studies in Family Planning, 27(6), 291-306.

Berrington, A. (2004). Perpetual postponers? Women's, men's and couple's fertilità intentions and subsequent fertility behaviour. Population Trends, 117: 9-19.

Bertocchi, G., Brunetti M., \& Torricelli, C. (2012). It is money or brains? The determinants of intra-family bargaining. Unpublished manuscript.

Billari, F., Philipov, D., \& Testa, M.R. (2009). Attitudes, norms and perceived behavioural control: Explaining fertility intentions in Bulgaria. European Journal of Population, 25(4), 439-465.

Bulatao, R.A. (1981). Values and disvalues of children in successive childbearing decisions. Demography, 18(1), 1-25.

Caltabiano, M., Castiglioni, M., \& Rosina, A. (2009). Lowest-Low Fertility. Signs of a recovery in Italy? Demographic Research, 21(23), 681-718. 
Cavalli, L. (2010). Why not having another child? The economics of fertility intentions for individuals and couples in Italy: a mixed method approach. Unpublished doctoral thesis. Milan: Università Cattolica del Sacro Cuore.

Cavalli L., \& Rosina, A. (2011). An Analysis of Reproductive Intentions of Italian Couples. Population Review, 50(1), 21-39.

Coombs, L.C. \& Chang, M.C. (1981). Do husbands and wives agree? Fertility attitudes and later behaviour. Population and Environment, 4(2), 109-127.

Corijn, M., A.C. Liefbroer \& De Jong Gierveld, J. (1996). It takes two to tango, doesn't it? The influence of couple characteristics on the timing of the birth of the first child. Journal of Marriage and the Family, 58: 117-126.

Davidson, A.R. \& Beach, L.R. (1981). Error patterns in the prediction of fertility behaviour. Journal of Applied Social Psychology, 11: 475-488.

Del Boca, D., S. Pasqua \& Pronzato, C. (2004). Why are fertility and women's employment rates so low in Italy? Lessons from France and the U.K. IZA Discussion Papers 1274.

De Rose, A., F., Racioppi, \& Zanatta, A.L. (2008). Italy: Delayed adaptation of social institutions to changes in family behaviour. Demographic Research, 19(19), 665-704.

De Santis, G. (2004). The monetary cost of children. Theory and empirical estimates for Italy. Genus, 60(1), 161-183.

Dommermuth, L., Klobas J., \& Lappegård, T. (2011). Now or later? The Theory of Planned Behavior and timing of fertility intentions. Advances in Life Course Research, 16:42-53.

EUROSTAT (2011). New measures of labour market attachment. 3 new Eurostat indicators to supplement the unemployment rate. Statistics in focus. 57.

Fisher, K. (2000). Uncertain aims and negotiation: birth control practices in Britain, 19251950. Population and Development Review 26(2), 295-317.

Fraboni, R. \& Rosina, A. (2006). Age at first union and fatherhood in a very low fertility context. Genus LXII(3-4): 87-109.

Fried, E.S., S.L. Hofferth \& Udry, J.R. (1980). Parity-specific and two-sex utility models of reproductive intentions. Demography, 17(1), 1-11.

Fried, E.S., \& Udry, J.R. (1979). Wives' and Husbands' expected costs and benefits of childbearing predictors of pregnancy. Social Biology, 26: 256-274.

Jansen, M., \& Liefbroer, A.C. (2006). Couple's attitudes, childbirth, and the division of labour. Journal of Family Issues, 27(11), 1487-1511. 
Lundberg, S. \& Pollak, R.A. (1996). Bargaining and distribution in marriage. Journal of Economic Perspectives, 10(4),139-158.

Dalla Zuanna, G., \& Micheli, G.A. (2004) Strong family and low fertility: a paradox?, Kluwer Academic Press, Dordrecht.

Miller, W.B. (1994). Childbearing motivations, desires, and intentions: a theoretical framework. Genetic, Social, and General Psychology Monographs, 120(2), 223-258.

Miller, W.B. (2011a). Comparing the TPB and the T-D-I-B framework. Vienna Yearbook of Population Research, 9: 19-29.

Miller, W.B. (2011b). Differences between fertility desires and intentions: Implications for theory, research, and policy. Vienna Yearbook of Population Research, 9: 75-98.

Miller, W.B., \& Pasta, D.J. (1996). Couple disagreement: effects on formation and implementation of fertility decisions. Personal Relationships, 3: 307-336.

Miller, W.B., L.J. Severy, \& Pasta, D.J. (2004). A framework for modeling fertility motivation in couples. Population Studies, 58(2), 193-205.

Morgan, S.P. (1985). Individual and couple intentions for more children: a research note. Demography, 22(1), 125-132.

Morgan, S. P. (2003). Is low fertility a twenty-first-century demographic crisis? Demography, 40, 589-604.

Naldini, M., \& Rosina, A. (2011). Famiglie e generazioni: tra vecchi patti di solidarietà e nuove forme di disuguaglianza. In: Atti del Convegno intermedio SIS "La statistica nei 150 anni dall'Unità d'Italia”, Bologna 8-10 June, 2011.

Namboodiri, N.K. (1972). Observations on the economic framework for fertility analysis. Population Studies, 26(2), 185-206.

Neal, A.G., \& Groat, H.T. (1980). Fertility decision making, unintended births, and the social drift hypothesis: a longitudinal study. Population and Environment, 3(3-4), 221-236.

OECD (2006). Live longer, work longer. Paris: OECD.

Philipov, D. (2011). Theories on fertility intentions: A demographer's perspective. Vienna Yearbook of Population Research, 9: 37-45.

Pinnelli, A. (1995). Women's condition, low fertility, and emerging union patterns in Europe. In K.O. Mason \& A.M. Jensen (Ed.), Gender and family change in industrialized societies, Oxford: Clarendon Press.

Rijken, A.J., \& Thomson, E. (2010). Partners' relationship and childbearing. Social Science Research, 40(2),485-497. 
Rijken, A.J. \& Liefbroer, A.C. (2009) The effects of relationship quality on fertility. European Journal of Population, doi:10.1007/s10680-008-9156-8.

Rindfuss, R.R., P.S. Morgan, \& Swicegood, G. (1988). First births in America: changes in the timing of parenthood. Berkeley and Los Angeles: University of California Press.

Ryder, N. (1973). A critique of the National Fertility Study. Demography, 10(4), 495-506.

Rosina, A. \& Testa, M.R. (2009). Couples' first child intentions and disagreement: an analysis of the Italian case. European Journal of Population, 25(4), 487-502.

Rosina, A. (2004). Family Formation in Italy: A Cohort Approach, In G. Dalla Zuanna \& G.A. Micheli (Ed.), Strong family and low fertility: a paradox?, Kluwer Academic Press, Dordrecht.

Saraceno, C. (1994). The ambivalent familism of the Italian welfare state. Social Politics, 1(1): 60-82

Schoen, R., N. M. Astone, Y.J., Kim, C.A., Nathanson \& Fields, J.M. (1999). Do Fertility Intentions Affect Fertility Behavior? Journal of Marriage and the Family, 61(3), 790-799.

Testa, M.R. (2010). She wants, he wants: Couple's childbearing desires in Austria. VID Working Papers, N.3.

Testa, M.R. (2006). Childbearing preferences and family issues in Europe. Special Eurobarometer 253/Wave 65.1 - TNS Opinion \& Social, European Commission.

Testa, M. R. (2012a). Couple disagreement about short-term fertility desires in Austria: Effects on intentions and contraceptive behaviour. Demographic Research, 26(3), 63-98.

Testa, M.R. (2012b). Childbearing preferences and family size in Europe: evidence from the 2011 Eurobarometer survey. European Demographic Research Paper 1. Vienna Institute of Demography of the Austrian Academy of Sciences.

Testa, M.R., Cavalli L. \& Rosina, A. (2011). Couples' childbearing behaviour in Italy: which of the partners is leading it? Vienna Yearbook of Population Research, 9: 157-178.

Thomson, E., E. McDonald, \& Bumpass, L.L. (1990). Fertility desires and fertility: hers, his and theirs. Demography, 27(4), 579-588.

Thomson, E. (1997). Couple childbearing desires, intentions and births. Demography, 34(3), 343-354.

Thomson, E. \& Hoem, J. (1998). Couple childbearing plans and births in Sweden. Demography, 35(3), 315-322.

Tomassini, C., D. Wolf, \& Rosina, A. (2003). Parental housing assistance and parent-child proximity in Italy, Journal of Marriage and Family, 65(3), 700-715. 
Townes, B.D., L.R. Beach, F.L. Campbell \& Wood, R.L. (1980). Family building: a social psychological study of fertility decisions. Population and Environment, 3(3-4), 210-220.

Voas, D. (2003). Conflicting preferences: a reason fertility tends to be too high or too low. Population and Development Review, 29(4), 627-646.

Zabin, L.S., Huggins, G.R., Emerson, M.R., \& Cullins, V.E. (2000). Partner effects on a woman's intention to conceive: 'Not with this partner'. Family Planning Perspectives, doi:10.2307/2648147. 


\section{APPENDIX}

\section{Robustness of the results to a different definition of disagreement}

The findings described above are robust to a different definition of disagreement, which considers any discrepancy between partners' answers irrespective of whether the answers go in the opposite direction (Scheme A.1).

Scheme A.1: Definition of disagreement as any discrepancy between partners' answers to the item: "Do you intend to have a child in the next three years?"

\begin{tabular}{|c|c|c|c|c|}
\hline $\begin{array}{l}\text { Man } \\
\text { Woman }\end{array}$ & Definitely no & Probably no & Probably yes & Certainly yes \\
\hline Definitely no & Both no & \multicolumn{3}{|c|}{$\mathrm{M}$ wants more than $\mathrm{W}$} \\
\hline Probably no & \multirow{3}{*}{\multicolumn{2}{|c|}{$\mathrm{M}$ wants less than $\mathrm{W}$}} & & \\
\hline Probably yes & & & Both yes & \\
\hline Certainly yes & & & & Both yes \\
\hline
\end{tabular}

Moreover, as seen for the disagreement defined by the answers going in opposite directions, the disagreement effects did not change in couples in which the partners shared equal gender roles.

In addition, we examined the effect of disagreement depending on whether the answers given by the partners were in adjacent categories (definitely no vs. probably no; probably no vs. probably yes, etc.) or differed by more than one level (e.g., definitely no vs. certainly yes; probably no vs. certainly yes, etc.). We found that the effect of disagreement did not change in these two sub-groups. It is worth noting that at parity zero, the discrepancy between the partners' answers was larger than one child in most of the cases (80\%), while among couples who had already had children the difference between partners' answers was larger than one child in only $20 \%$ of the cases. This result suggests that couples who had already started their reproduction career might have reached a general agreement about their completed family size. 


\section{VIENNA INSTITUTE OF DEMOGRAPHY}

\section{Working Papers}

Kuhn, Michael and Klaus Prettner, Growth and Welfare Effects of Health Care in Knowledge Based Economies, VID Working Paper 06/2012.

Sander, Nikola and Martin Bell, Age, Period and Cohort Effects on Migration of the Baby Boomers in Australia, VID Working Paper 05/2012.

Grafeneder-Weissteiner, Theresa, Ingrid Kubin, Klaus Prettner, Alexia Prskawetz, and Stefan Wrzaczek, Coping with Inefficiencies in a New Economic Geography Model, VID Working Paper 04/2012.

Goujon, Anne, Éric Caron Malenfant, and Vegard Skirbekk, Towards a Catholic North America? Projections of Religion in Canada and the US beyond the Mid-21st Century, VID Working Paper 03/2012.

Di Giulio, Paola, Christoph Bühler, Andreas Ette, Romina Fraboni, and Kerstin Ruckdeschel, Social Capital and Fertility Intentions: The Case of Italy, Bulgaria, and West Germany, VID Working Paper 02/2012.

Abel, Guy J., Estimating Global Migration Flow Tables Using Place of Birth Data, VID Working Paper 01/2012.

Ediev, Dalkhat M., At Modal Age at Death, the Hazard Rate is Determined by its Derivative, VID Working Paper 08/2011.

Zeman, Kryštof, Tomáš Sobotka, Richard Gisser, Maria Winkler-Dworak, and Wolfgang Lutz, Geburtenbarometer Vienna: Analysing Fertility Convergence between Vienna and Austria, VID Working Paper 07/2011 (English and German versions available).

Feichtinger Gustav, Michael Kuhn, Alexia Prskawetz, and Stefan Wrzaczek, The Reproductive Value as Part of the Shadow Price of Population, VID Working Paper 06/2011.

Barakat, Bilal, Time is Money: Could Deferred Graduate Retirement Finance Higher Education?, VID Working Paper 05/2011.

Riosmena, Fernando, Maria Winkler-Dworak, Alexia Prskawetz, and Gustav Feichtinger, The Impact of Policies Influencing the Demography of Age Structured Populations: Lessons from Academies of Science, VID Working Paper 04/2011.

The Vienna Institute of Demography Working Paper Series receives only limited review. Views or opinions expressed herein are entirely those of the authors. 